\title{
Screening and Management of Gestational Diabetes Mellitus after Bariatric Surgery
}

\author{
Katrien Benhalima ${ }^{1, *}\left(\mathbb{D}\right.$, Caro Minschart ${ }^{1}$, Dries Ceulemans ${ }^{2}$, Annick Bogaerts ${ }^{3,4,5} \oplus$, \\ Bart Van Der Schueren ${ }^{1,6}$, Chantal Mathieu ${ }^{1}$ and Roland Devlieger ${ }^{2}$ \\ 1 Department of Endocrinology, University hospital Gasthuisberg, KU Leuven, Herestraat 49, 3000 Leuven, \\ Belgium; caro.minschart@kuleuven.be (C.M.); bart.vanderschueren@uzleuven.be (B.V.D.S.); \\ chantal.mathieu@uzleuven.be (C.M.) \\ 2 Department of Obstetrics \& Gynecology, University hospital Gasthuisberg, KU Leuven, Herestraat 49, \\ 3000 Leuven, Belgium; dries.ceulemans@uzleuven.be (D.C.); roland.devlieger@uzleuven.be (R.D.) \\ 3 Department of Development and Regeneration, KU Leuven, Herestraat 49, 3000 Leuven, Belgium; \\ annick.bogaerts@kuleuven.be \\ 4 Faculty of Medicine and Health Sciences, Centre for Research and Innovation in Care (CRIC), University of \\ Antwerp, 2000 Antwerp, Belgium \\ 5 Faculty of Health and Social Work, research unit Healthy Living, University Colleges Leuven-Limburg, \\ 3001 Leuven, Belgium \\ 6 Department of Chronic Diseases, Metabolism and Ageing, KU Leuven, Herestraat, 49, 3000 Leuven, Belgium \\ * Correspondence: katrien.benhalima@uzleuven.be; Tel.: +32-016-340-614
}

Received: 3 September 2018; Accepted: 9 October 2018; Published: 11 October 2018

check for updates

\begin{abstract}
Gestational diabetes mellitus (GDM) is a frequent medical complication during pregnancy. This is partly due to the increasing prevalence of obesity in women of childbearing age. Since bariatric surgery is currently the most successful way to achieve maintained weight loss, increasing numbers of obese women of childbearing age receive bariatric surgery. Bariatric surgery performed before pregnancy significantly reduces the risk to develop GDM but the risk is generally still higher compared to normal weight pregnant women. Women after bariatric surgery therefore still require screening for GDM. However, screening for GDM is challenging in pregnant women after bariatric surgery. The standard screening tests such as an oral glucose tolerance test are often not well tolerated and wide variations in glucose excursions make the diagnosis difficult. Capillary blood glucose measurements may currently be the most acceptable alternative for screening in pregnancy after bariatric surgery. In addition, pregnant women after bariatric surgery have an increased risk for small neonates and need careful nutritional and foetal monitoring. In this review, we address the risk to develop GDM after bariatric surgery, the challenges to screen for GDM and the management of women with GDM after bariatric surgery.
\end{abstract}

Keywords: gestational diabetes mellitus; screening; bariatric surgery; pregnancy; obesity

\section{Introduction}

Obesity is increasing at an alarming rate worldwide and has doubled since 1980, with a dramatic increase now also seen in low- and middle-income countries, particularly in urban settings [1]. Worldwide about $40 \%$ of adult women aged 18 years and older are overweight and $15 \%$ are obese [1]. Obesity is associated with increased risks for infertility, congenital malformations, miscarriages, GDM, preeclampsia and caesarean deliveries [1-3]. Severely obese women with a body mass index (BMI) $\geq$ $40 \mathrm{~kg} / \mathrm{m}^{2}$ or BMI $\geq 35 \mathrm{~kg} / \mathrm{m}^{2}$ with comorbidities and who obtained insufficient weight loss through lifestyle interventions, are eligible for weight-loss surgery with bariatric surgery. Since bariatric surgery is the most successful way to obtain significant and maintained weight loss, increasing numbers of 
obese women of childbearing age receive bariatric surgery. Women aged 18-45 years undergo now more than 50,000 inpatient bariatric surgery procedures a year in the United States, accounting for approximately half of all bariatric procedures [4]. In addition, fertility in obese women generally improves after bariatric surgery, increasing the numbers of obese women who become pregnant after surgery [4].

Gestational diabetes mellitus (GDM) was historically defined as 'any degree of glucose intolerance with onset or first recognition during pregnancy' [5]. Due to the increasing prevalence of type 2 diabetes mellitus (T2DM) in women of childbearing age, many international associations recommend now to screen for overt diabetes at first prenatal contact [6-9]. GDM is therefore now commonly defined as diabetes diagnosed in the second or third trimester of pregnancy provided that diabetes early in pregnancy has been excluded [7-9]. Women who develop GDM in late gestation, often already have a subclinical metabolic dysfunction prior to conception compared with women with normal glucose tolerance. Because of the important decrease in insulin sensitivity in normal pregnancy, the predisposing baseline insulin resistance is further exacerbated and/or in combination with beta-cell dysfunction, results in the development of GDM [10,11]. It has clearly been demonstrated that treatment of GDM between 24-28 weeks of pregnancy can reduce adverse pregnancy outcomes, especially large-for-gestational age infants (LGA) and preeclampsia [12,13]. Shortly after the delivery, the glucose values are generally restored to normal but women with GDM are at increased risk of developing T2DM later in life [14]. GDM seems also to be related to childhood obesity but mainly in case of coexisting maternal obesity $[15,16]$. The 'Hyperglycaemia and Adverse Pregnancy Outcomes' (HAPO) study showed a continuous and graded relationship between the maternal hyperglycaemia and the risk for an adverse perinatal outcome [17]. Based on the HAPO study, the 'International Association of Diabetes and Pregnancy Study Groups' (IADPSG) recommended a universal one-step approach with the $75 \mathrm{~g}$ oral glucose tolerance test (OGTT) with the use of more stringent diagnostic criteria for GDM [6]. The IADPSG recommendation for GDM screening has now been endorsed by several associations including by the World Health Organization (WHO) [7-9,18]. Recent studies using the IADPSG screening strategy for GDM, have shown GDM rates of $25-39 \%$ in obese women $[19,20]$. Women often remain overweight after bariatric surgery and the risk to develop GDM is generally still higher compared to normal weight pregnant women. However, many uncertainties remain concerning screening and management of GDM in women after bariatric surgery. In this review, we address the risk to develop GDM after bariatric surgery, the challenges to screen for GDM and the management of women with GDM after bariatric surgery. As this is not a systematic review of the literature, this review is not intended to be fully comprehensive of the topic at hand. The available literature on GDM after bariatric surgery was searched in June and July 2018 through Medline and all relevant studies (without exclusion of any study type) available in English were included.

\section{The Risk of Adverse Pregnancy Outcomes in Obese Women with GDM}

GDM increases the risk of LGA, since the maternal glucose crosses the placenta and stimulates foetal insulin secretion which acts as a growth factor. LGA increases risks of shoulder dystocia and caesarean deliveries [17,21]. GDM is also associated with pregnancy-induced hypertension and pre-eclampsia. Short-term risks for the baby include neonatal hypoglycaemia, hyperbilirubinaemia and respiratory distress syndrome $[17,21]$. As obesity is not only associated with hyperglycaemia but also with hyperlipidaemia, lipids may provide additional substrates for foetal overgrowth. This is confirmed by recent studies showing that in GDM there is a preferential activation of lipid genes in the placenta in contrast to the activation of glucose metabolic pathways [10]. Several studies have shown that both maternal GDM and obesity are independently associated with adverse pregnancy outcomes and that the combination of obesity and GDM shows a greater risk of adverse pregnancy outcomes than either obesity or GDM alone [22,23]. Since the placenta and other tissues may already be programmed in early pregnancy, achieving optimal metabolic health before a planned pregnancy, might be the best option to obtain good pregnancy outcomes. Although several randomized controlled 
trials (RCT's) investigating lifestyle interventions in overweight or obese women during pregnancy, resulted in a significant reduction in gestational weight gain, this was generally not associated with a reduction in the rate of GDM or with improvement of other pregnancy outcomes $[19,20,24,25]$. Women with overweight or obesity should therefore optimally lose weight before pregnancy to improve pregnancy outcomes.

\section{Bariatric Surgery Procedures}

There are three different types of bariatric surgery procedures: restrictive, malabsorptive and combined restrictive-malabsorptive procedures. Restrictive procedures, such as sleeve gastrectomy, vertical banded gastroplasty (VBG) and adjustable gastric banding (ABG), promote weight loss by decreasing the gastric volume and thereby limiting food intake. They are generally considered safer and less complicated to perform but they do have the disadvantage that high-energy foods may bypass the restriction [4,26]. Malabsorptive procedures, such as biliopancreatic diversion (BPD), cause weight loss by bypassing a significant portion of the small bowel but they induce important malabsorption. Purely malabsorptive procedures are therefore now rarely performed $[4,26]$. Worldwide, most procedures are currently of the combined type, with the laparoscopic Roux-en-Y gastric bypass (RYGB) [4]. RYGB is in general superior to restrictive procedures in terms of excess weight loss but is associated with more surgical complications [4]. The Swedish obese subjects (SOS) study has shown an average maximum weight loss after $1-2$ years of $32 \%$ for RYGB, $25 \%$ for VBG and $20 \%$ for AGB as compared to a $1-2 \%$ change in body weight resulting from conventional lifestyle interventions [27]. A 10-year follow-up found weight loss had stabilized at $25 \%, 16 \%$ and $14 \%$, respectively, for the three procedures [27].

\subsection{Pregnancy Outcomes after Bariatric Surgery}

There is now evidence that bariatric surgery performed before pregnancy is not only associated with several benefits but also with some important harms. Bariatric surgery can lead to complications during pregnancy such as internal hernias, intestinal obstructions, hyperemesis, cholelithiasis and problems with position and function of the gastric band that may require revision [28]. A high index of suspicion for gastrointestinal surgical complications is therefore needed in women after bariatric surgery who present with abdominal pain during pregnancy [29].

In addition, several nationwide register-based cohort studies have shown that bariatric surgery is associated with lower risks for foetal macrosomia, GDM and hypertensive disorders but with increased rates of small-for-gestational age (SGA) infants and preterm delivery [30-32]. The most recent systematic review and meta-analysis from 2018 included 20 cohort studies (with 8364 women who had bariatric surgery) and pooled odds ratios (OR) for each outcome were estimated with the use of the Dersimonian and Laird random effects. To aid interpretation, the authors also computed the pooled absolute risk difference and reported this as the number needed to benefit or the number needed to harm. This systematic review showed that bariatric surgery, with patients matched for pre-surgery BMI, resulted in a significant reduction of LGA infants [OR 0.31 (95\% confidence interval (CI) $0.17-0.59)$ ], with a number needed to benefit of 5, gestational hypertension [OR 0.38 (95\% CI 0.19-0.76)], with a number needed to benefit of 11 and caesarean delivery rates [OR 0.50 (95\% CI 0.38-0.67)], with a number needed to benefit of 9 [33]. This systematic review also confirmed that bariatric surgery is associated with a significant increase in SGA infants [OR 2.16 (95\% CI 1.34-3.48)], with a number needed to harm of 21 and preterm deliveries [OR 1.35 (95\% CI 1.02-1.79)], with a number needed to harm of 35 . No differences in rates of preeclampsia, neonatal intensive care unit admissions, stillbirths, malformations and neonatal deaths were seen [33]. This suggests that bariatric surgery is not risk free and regular foetal monitoring during pregnancy is therefore warranted. Given that the risks of SGA infants and preterm deliveries were also increased when matching for pre-pregnancy weight, suggests that bariatric surgery as such is associated with adverse obstetric outcomes and not only through weight reduction [33]. 
Few studies have compared pregnancy outcomes between different type of bariatric surgery procedures and they generally showed comparable outcomes between malabsorptive and restrictive procedures [34-36]. However, a secondary analyses of the most recent systematic review showed that malabsorptive surgeries resulted in a significantly greater increase in SGA infants [OR 2.39 (95\% CI 1.94-2.94)] and a significantly greater decrease in LGA infants [OR 0.28 (95\% CI 0.22-0.36)] compared with restrictive surgeries [33]. Since the risk for SGA associated with bariatric surgery cannot only be attributed to the weight loss, this may also be related to micronutrient deficiencies during pregnancy [37]. This could therefore also explain the higher risk for SGA infants in malabsorptive procedures compared to restrictive procedures.

\subsection{The Risk for GDM after Bariatric Surgery}

Most studies have shown that bariatric surgery can significantly decrease the risk for GDM compared to the preoperative risk or compared to obese controls [28,30,32,38-49]. Table 1 gives an overview of the studies evaluating the risk for GDM after bariatric surgery since 2010. Some studies have demonstrated that bariatric surgery can decrease the risk for GDM to a rate equivalent with the general population $[30,44,49]$ while other studies still showed a higher risk for GDM in women after bariatric surgery compared to normal weight controls $[28,42,43]$. The reduction in the rate of GDM also persists into a consecutive postoperative pregnancy [41]. The most recent systematic review matching to pre-bariatric surgery weight, showed that bariatric surgery resulted in a significant reduction in GDM with an OR of 0.21 (95\% CI 0.11-0.37) with a number needed to benefit of 5 [33]. When women were matched for pre-pregnancy BMI, bariatric surgery was no longer associated with a lower rate of GDM [33]. This suggests that the lower risk for GDM is primarily due to weight loss rather than due to a specific mechanism inherent to the postoperative status. The interval from surgery to conception does not appear to have a significant effect on the rate of GDM as similar rates of GDM reduction were seen during and after the first year after bariatric surgery $[39,50]$. From current evidence, we can therefore conclude that bariatric surgery is an effective way to reduce the risk for GDM in obese women. However, since more than half of all women of childbearing age after bariatric surgery are still obese, the risk to develop GDM will in general still be higher compared to normal weight pregnant women [51]. All pregnant women with bariatric surgery should therefore undergo screening for GDM.

Table 1. Overview of studies evaluating the risk for GDM after bariatric surgery since 2010.

\begin{tabular}{|c|c|c|c|c|c|c|}
\hline Study & Year & Country & Intervention Group & Comparison Group & $\begin{array}{c}\text { GDM } \\
\text { Cases N (\%) }\end{array}$ & $\begin{array}{c}\text { GDM } \\
\text { Controls N (\%) }\end{array}$ \\
\hline Burke et al. [38] & 2010 & USA & 354 postoperative pregnancies & 346 preoperative pregnancies & $28(8.0)$ & $94(27.0)$ \\
\hline Santulli et al. [28] & 2010 & France & 24 pregnancies after RYGB & $\begin{array}{l}120 \text { normal BMI controls } \\
120 \text { BMI-matched controls }\end{array}$ & $2(8.3)$ & $\begin{array}{r}6(5.0) \\
10(8.3)\end{array}$ \\
\hline Lapolla et al. [49] & 2010 & Italy & 83 pregnancies after LAGB & $\begin{array}{l}120 \text { obese women } \\
858 \text { normal controls }\end{array}$ & $5(6.0)$ & $60(50.0) \mathrm{NR}$ \\
\hline Sheiner et al. [39] & 2011 & Israel & $\begin{array}{l}104 \text { pregnancies }<\text { first } \\
\text { postoperative year }\end{array}$ & $\begin{array}{l}385 \text { pregnancies }>\text { first } \\
\text { postoperative year }\end{array}$ & $11(10.5)$ & $28(7.3)$ \\
\hline $\begin{array}{l}\text { Aricha-Tamir et al. } \\
\text { [40] }\end{array}$ & 2012 & Israel & 144 postoperative pregnancies & $\begin{array}{c}144 \text { preoperative pregnancies } \\
\text { (same women) }\end{array}$ & $8(5.7)$ & $28(19.3)$ \\
\hline Josefsson et al. [42] & 2013 & Sweden & 310 firstborns after surgery & 270,805 Swedish firstborns & $17(5.9)$ & $3.514(1.4)$ \\
\hline Kjaer et al. [32] & 2013 & Denmark & 339 postoperative pregnancies & 1277 matched controls & $30(8.9)$ & $91(7.1)$ \\
\hline Amsalem et al. [41] & 2014 & Israel & $\begin{array}{c}109 \text { first pregnancies } \\
\text { postoperative } \\
109 \text { s pregnancies postoperative }\end{array}$ & 109 preoperative pregnancies & $\begin{array}{l}6(5.6) \\
7(6.6)\end{array}$ & $21(19.0)$ \\
\hline Berlac et al. [43] & 2014 & Denmark & 415 singletons after RYGB & $\begin{array}{c}827 \text { adipose controls } \\
829 \text { normal weight controls }\end{array}$ & $38(9.2)$ & $\begin{array}{l}67(8.1) \\
11(1.3)\end{array}$ \\
\hline Shai D et al. [46] & 2014 & Israel & 326 postoperative pregnancies & 1612 obese controls & $33(10.1)$ & $237(14.7)$ \\
\hline Johansson et al. [30] & 2015 & Sweden & 596 postoperative births & 2356 matched control births & $11(1.9)$ & $157(6.8)$ \\
\hline Adams et al. [44] & 2015 & USA & $\begin{array}{l}295 \text { women with births before } \\
\text { and after RYGB }\end{array}$ & 295 control births & $10(3.4)$ & $26(8.8)$ \\
\hline
\end{tabular}


Table 1. Cont.

\begin{tabular}{ccccccc}
\hline Study & Year & Country & Intervention Group & Comparison Group & $\begin{array}{c}\text { GDM } \\
\text { Cases N (\%) }\end{array}$ & $\begin{array}{c}\text { GDM } \\
\text { Controls N (\%) }\end{array}$ \\
\hline $\begin{array}{c}\text { Abenhaim A et al. } \\
\text { [45] }\end{array}$ & 2016 & Canada & 9587 postoperative pregnancies & $\begin{array}{c}8,244,661 \text { controls } \\
221,580 \text { morbid obese } \\
\text { controls }\end{array}$ & $\begin{array}{c}1011(10.5) \\
\text { 224,758 (2.7) } \\
18,936(8.5)\end{array}$ \\
\hline Parker MH et al. [47] & 2016 & USA & 1585 postoperative pregnancies & 185,120 obese controls & $119(7.3)$ & $8145(4.4)$ \\
\hline Chevrot A et al. [48] & 2016 & France & $\begin{array}{c}\text { 139 postoperative pregnancies } \\
\text { (58 RYGB, 81 LAGB and } 9 \\
\text { sleeve gastrectomy) }\end{array}$ & $\begin{array}{c}139 \text { obese controls matched } \\
\text { for pre-surgery BMI }\end{array}$ & $17(12)$ & $32(23)$ \\
\hline
\end{tabular}

GDM: gestational diabetes mellitus; RYGB: laparoscopic Roux-en-Y gastric bypass; LAGB: laparoscopic adjustable gastric banding; BMI: body mass index $\left(\mathrm{kg} / \mathrm{m}^{2}\right)$; NR: not reported.

\subsection{How to Screen for GDM after Bariatric Surgery?}

There are no specific guidelines on screening for GDM in women with a history of bariatric surgery. The standard test for the diagnosis of GDM is the OGTT but this is generally not well tolerated in bariatric surgery patients. Evaluation of the tolerance of the OGTT in 128 bariatric surgery patients of which $30 \%$ were pregnant, showed adverse events in $65 \%$, of which the most common were nausea $(38 \%)$, dizziness $(30 \%)$, weakness $(26 \%)$ and diarrhoea (23\%) [52]. The poor tolerance of the OGTT in patients with bariatric surgery is due to the high risk for early and late dumping after ingestion of the glucose load. Early dumping results from accelerated gastric emptying of hyperosmolar content into the duodenum or small bowel, followed by fluid shifts from the intravascular compartment into the intestinal lumen. Symptoms appear 10-60 min after food intake and can include abdominal pain, nausea, diarrhoea, fatigue, palpitations and tachycardia. Late dumping occurs 1-3 h after a meal, when a hyperinsulinaemic response to ingested carbohydrates produces postprandial reactive hypoglycaemia [4,51].

Dumping also causes wide variations in glucose excursions on the OGTT in pregnant women with bariatric surgery, making it very challenging to make a diagnosis. A large retrospective cohort study showed that pregnant women after RYGB had lower fasting glucose levels compared with lean, obese and BMI-matched controls but had more often a high glucose excursion at $1 \mathrm{~h}$ and $55 \%$ had a reactive hypoglycaemia at $2 \mathrm{~h}$ [53]. Other studies have confirmed high rates of reactive hypoglycaemia on the OGTT in $50-58 \%$ of pregnant women after bariatric surgery [54,55]. In addition, a recent study has shown that the risk for reactive hypoglycaemia was significantly higher in women with RYGB $(83 \%)$ than among women with prior sleeve gastrectomy (54\%) or ABG (12\%) [55]. Preservation of the pyloric valve during the sleeve gastrectomy procedure might partly account for the lower risk for hypoglycaemia compared to RYGB. However, the risk for hypoglycaemia was still high in pregnant women with prior sleeve gastrectomy, suggesting that sleeve gastrectomy still causes important dumping in pregnancy [4]. The study also showed that the time from surgery to conception was significantly shorter among women with a reactive hypoglycaemia during the OGTT. Women with a reactive hypoglycaemia had also significantly higher rates of SGA infants (11.9\% compared to $1.7 \%)$ [55]. The potential association found between hypoglycaemia and poor foetal growth warrants further investigation in larger studies. It also remains unclear whether maintaining a tight euglycaemic balance and avoiding hypoglycaemia will favourably impact foetal outcomes in women with bariatric surgery.

A recent study showed that by using the IADPSG criteria for GDM, $50 \%$ of all pregnant women with a history of bariatric surgery would be diagnosed with GDM but this diagnosis did not affect pregnancy outcomes [54]. These data suggest that alternative diagnostic criteria might be needed for women with bariatric surgery. Current evidence therefore suggest that an OGTT with the IADPSG criteria should not be used for screening and diagnosis of GDM in women with bariatric surgery, as this leads to inaccurate results and an increased risk for a reactive hypoglycaemia [51,54]. Moreover, this will lead to a high prevalence of GDM in women with bariatric surgery without clear evidence that treatment has a favourable impact on pregnancy outcomes.

Several professional associations recommend a two-step approach for screening for GDM, using a non-fasting $50 \mathrm{~g}$ glucose challenge test (GCT) to determine whether an OGTT should be performed [56]. 
The GCT is easier to perform and is generally better tolerated than an OGTT [57]. The GCT could therefore be used as an alternative to the OGTT in women with bariatric surgery. However, there are currently no data available on the tolerance of the GCT in women with bariatric surgery nor on potential glucose variations after the GCT in this population.

A small study has reported that continuous glucose monitoring (CGM), used in pregnant women with RYGB for 3-7 days at 24-28 weeks, showed similar glycaemic profiles as described in non-pregnant RYGB patients [58]. The authors suggest to use the time spent above $7.8 \mathrm{mmol} / \mathrm{L}$ as a surrogate for the diagnosis of impaired glucose tolerance during pregnancy after bariatric surgery since foetal exposure to such glucose excursions have been associated with foetal overgrowth [58]. Larger studies are needed to confirm these data and validate CGM thresholds for the diagnosis of GDM. In addition, CGM is expensive and not widely available [51]. No data are yet available on the potential usefulness of the Freestyle Libre Flash glucose monitoring system for the diagnosis of GDM after bariatric surgery. A case report has shown that the Flash sensor might be helpful in the management of dumping syndrome with hypoglycaemia in a pregnancy after RYGB [59].

Since there is currently lack of adequate tests to screen for GDM, we suggest a pragmatic approach to evaluate dysglycaemia in pregnant women with bariatric surgery (Figure 1). Since women with bariatric surgery often remain overweight, we first recommend to screen for overt diabetes at first prenatal visit by measuring the fasting glycaemia or glycated haemoglobin (HbA1c). HbA1c has the advantage that it can used in the non-fasting state but it is less sensitive than fasting glycaemia to screen for T2DM. HbA1c is also not recommended for screening for GDM as it lacks sensitivity [7]. In addition, the HAPO study showed that associations with adverse outcomes were significantly stronger with glucose measures than with Hba1c [17].

First prenatal visit: screening for unknown overt diabetes in all women with bariatric surgery:

Fasting glycaemia $\geq 7.0 \mathrm{mmol} / \mathrm{L}$ or $\mathrm{HbA}_{\mathrm{lc}} \geq 6.5 \%(47 \mathrm{mmol} / \mathrm{mol})$

Treat as diabetes

If normal

24-28 weeks of pregnancy: recording of capillary blood glucose daily before and after meals for 3-7 days in all women with bariatric surgery

Thresholds for diagnosis and intervention:

Fasting glycaemia $\geq 5.3 \mathrm{mmol} / \mathrm{L}$

1-h after the meal $\geq 7.8 \mathrm{mmol} / \mathrm{L}$

2-h after the meal $\geq 6.7 \mathrm{mmol} / \mathrm{L}$

If abnormal

Treat as GDM

Figure 1. A pragmatic proposal for the evaluation of dysglycaemia in pregnant women after bariatric surgery. GDM: gestational diabetes mellitus.

Since women with bariatric surgery generally remain at high risk for GDM, we suggest to evaluate dysglycaemia later in pregnancy in all women with bariatric surgery by recording capillary blood 
glucose daily before and after meals during 3-7 days at 24-28 weeks of pregnancy [51]. For the diagnostic and intervention glycaemic targets, we propose to use the same targets for the treatment of GDM as recommended by the American Diabetes Association (ADA) (fasting glycaemia $<5.3 \mathrm{mmol} / \mathrm{L}$, 1-h after the meal $<7.8 \mathrm{mmol} / \mathrm{L}$ or 2 -h after the meal $<6.7 \mathrm{mmol} / \mathrm{L}$ ) [60]. CGM and capillary blood testing have not yet demonstrated to favourably impact on pregnancy outcomes. However, capillary blood glucose measurements may currently be the most acceptable alternative to the OGTT for screening in pregnancy after bariatric surgery [51]. More research is needed to better define dysglycaemia in a pregnancy after bariatric surgery.

\subsection{Treatment of GDM after Bariatric Surgery}

Initial treatment of GDM involves diet modification, glucose monitoring and moderate exercise. There is a paucity of evidence-based data concerning nutritional treatment for the general population with GDM. In general the recommendation is to follow the National Academy of Medicine revised guidelines from 2009 for weight gain during pregnancy, to reduce the caloric intake of obese women by approximately one-third while maintaining a minimum intake of 1600-1800 kcal per day, to limit the carbohydrate intake to $35-45 \%$ of total calories without compensatory increased intake of saturated fat, to avoid the intake of carbohydrates with a high glycaemic index and to perform daily moderate exercise for $30 \mathrm{~min}$ or more $[60,61]$.

If lifestyle is insufficient to maintain the glycaemic targets after 1-2 weeks, pharmacological therapy with insulin becomes necessary. Recent studies have suggested that metformin and glibenclamide (glyburide) may be safe and acceptable alternatives for insulin for the treatment of GDM [61]. However, the need for supplemental insulin in women on metformin is high and increased risks for neonatal hypoglycaemia and macrosomia have been reported in women treated with glibenclamide $[62,63]$. Moreover, there is a paucity of long-term follow-up data on children exposed to oral agents in utero and recent data suggest that exposure to metformin in utero might significantly increase the risk for overweight and obesity in 4-year offspring [64]. Insulin remains therefore the first choice when lifestyle measures are insufficient to achieve good glycaemic control.

Since women with bariatric surgery, have a higher risk for intrauterine growth restriction (IUGR) and SGA neonates, questions remain as to whether the management of GDM should be adapted for women with bariatric surgery. Data are needed on the most appropriate glycaemic targets for the treatment of GDM after bariatric surgery. It is currently unclear whether the glycaemic targets which are currently commonly used and recommended by the ADA, are also adequate for women after bariatric surgery or might be too strict and further enhance the risk for SGA neonates [60]. There are currently no RCT's that have investigated the impact of different glycaemic targets for the treatment of GDM on pregnancy outcomes in women after bariatric surgery.

\subsection{Nutritional Monitoring and Supplementation}

Bariatric surgery, in particular the malabsorptive procedures, lead to a high risk for deficiencies of several micronutrients (mainly vitamin B12, vitamin D and other fat-soluble vitamins, folate, calcium, iron and other trace elements) and macronutrients (mainly proteins and fat) $[65,66]$. Therefore, dietary counselling and supplementation are mandatory after bariatric surgery but compliance with follow-up remains difficult in this patient population. Due to concerns for potential nutritional deficiencies and adverse effects on the foetus during the period of rapid weight loss that typically lasts 6-18 months after surgery, it is generally recommended to avoid pregnancy following bariatric surgery for 12-24 months [4]. A large population-based retrospective cohort study showed that an operation-to-birth interval less than 2 years was associated with higher risks for prematurity, admission on the neonatal intensive care unit and SGA infants compared with longer intervals [67]. In contrast, several smaller studies found no association between a shorter time to conception and an increased risk for adverse pregnancy complications $[32,36,39,68,69]$. 
Several studies have evaluated specific evidence of micronutrient deficiencies in postoperative mothers and infants. However, these studies had small sample sizes and rarely compared them to a control population [70-73]. A higher risk for anaemia has been demonstrated in women after bariatric surgery (OR 3.4, 95\% CI 1.56-7.44) and reached 15\% after RYGB and $24 \%$ after BPD in a retrospective cohort of 115 subjects [70]. Low levels of vitamin B12 have also been reported in $11 \%$ to $15 \%$ of patients but the levels were not significant lower compared to a control population [71]. A prospective cohort study including 49 pregnant women with bariatric surgery showed that low circulating vitamin $\mathrm{K} 1$ is common and that supplementation during pregnancy can restore vitamin $\mathrm{K} 1$ in women with bariatric surgery, potentially protecting the foetus and new-born against intracranial haemorrhage [73]. A systematic review showed that the most common adverse neonatal outcomes related to maternal micronutrient deficiencies include visual complications (vitamin A), intracranial haemorrhage (vitamin K1), neurological and developmental impairment (vitamin B12) and neural tube defects (folate) [37]. However, the overall evidence in the systematic review was low as studies often did not provide sufficient information. The evidence on micronutrient deficiencies in pregnant and postpartum women after bariatric surgery and subsequent adverse neonatal outcomes remains therefore inconclusive. Nutritional supplementation may also not improve all pregnancy outcomes [74].

Guidelines generally recommend that patients who become pregnant following bariatric surgery should have nutritional surveillance and laboratory screening for deficiencies every trimester, including tests for iron, folate and B12, calcium and fat-soluble vitamins $[65,66]$. However, practice guidelines do not suggest specific supplementation during pregnancy and standard supplementation is generally recommended as for non-pregnant patients after bariatric surgery (Table 2) [65]. Based on the best available evidence and our clinical experience, we propose some suggestions for monitoring and supplementation of micronutrients in all women regardless of the type of bariatric surgery from preconception to the postpartum period (Table 3) [37].

Table 2. Recommended nutritional supplementation after bariatric surgery.

\begin{tabular}{cc}
\hline Nutrients & Recommended Supplementation \\
\hline Multivitamin tables (with iron, folic acid and thiamine) & 2 tables/day \\
Calcium & Calcium citrate $1200-1500 \mathrm{mg} /$ day \\
Vitamin D $3000 \mathrm{IU} /$ day & 3000 IU/day titrated to 25 -hydroxyvitamin D level \\
Vitamin B12 as needed & As needed for normal range \\
Iron supplement & $45-60 \mathrm{mg} /$ day \\
Protein intake & Minimal $60 \mathrm{~g} /$ day and up to $1.5 \mathrm{~g} / \mathrm{kg}$ ideal body \\
Vitamin A & weight per day \\
\end{tabular}

Table 3. Proposal of micronutrient monitoring and supplementation from preconception to postpartum in women after bariatric surgery.

\begin{tabular}{|c|c|c|c|}
\hline & Timing of Screening & $\begin{array}{l}\text { Monitoring of } \\
\text { Micronutrients }\end{array}$ & Supplementation \\
\hline Preconception & Every 6 months & $\begin{array}{c}\text { Vitamin A (preferably as } \\
\text { Beta carotene), D, B12, } \\
\text { folate, K1 and iron }\end{array}$ & $\begin{array}{l}\text { Multivitamin tablet with vitamin } \\
\text { B12 and folate with additional } \\
\text { supplements as needed }\end{array}$ \\
\hline During pregnancy & $\begin{array}{l}\text { Every trimester and additional } \\
\text { screening if low levels } \\
\text { despite supplement }\end{array}$ & $\begin{array}{l}\text { Vitamin A (preferably as } \\
\text { Beta carotene), D, B12, } \\
\text { folate, } \mathrm{K} 1 \text { and iron }\end{array}$ & $\begin{array}{l}\text { Multivitamin tablet with vitamin } \\
\text { B12 and folate with additional } \\
\text { supplements as needed }\end{array}$ \\
\hline Postpartum & $\begin{array}{l}\text { At } 6-12 \text { weeks in all women } \\
\text { additional screening at } 3-6 \\
\text { months if low levels despite } \\
\text { supplement yearly follow-up } \\
\text { if no deficiencies at } 6-12 \text { weeks }\end{array}$ & $\begin{array}{l}\text { Vitamin A (preferably as } \\
\text { Beta carotene), D, B12, } \\
\text { folate, } \mathrm{K} 1 \text { and iron }\end{array}$ & $\begin{array}{l}\text { Multivitamin tablet with vitamin } \\
\text { B12 and folate with additional } \\
\text { supplements as needed }\end{array}$ \\
\hline
\end{tabular}




\section{Conclusions}

Bariatric surgery is an effective way to reduce the risk for GDM in obese women. However, the risk of developing GDM is in general still higher in women after bariatric surgery compared to normal weight pregnant women. Standard screening with an OGTT is often not well tolerated and wide variations in glucose excursions make the diagnosis difficult. Capillary blood glucose measurements may currently be the most acceptable alternative for screening for GDM in pregnancy after bariatric surgery. Since women with bariatric surgery, have a higher risk for small neonates due to nutrient deficiencies, questions remain as to whether the management of GDM should be adapted for women with bariatric surgery. In particular, data are needed on the most appropriate glycaemic targets for the treatment of GDM to favourably impact pregnancy outcomes. More data are also needed on the optimal nutritional monitoring and supplementation strategy in preconception, during pregnancy and in the early postpartum period. The lack of specific guidelines concerning screening and management of GDM in women with bariatric surgery, highlights the need for more research for a better screening test and a better understanding of how to define and treat dysglycaemia in a pregnancy after bariatric surgery.

Author Contributions: K.B. and C.M. (Caro Minschart) did the literature review. K.B. wrote the first draft of the manuscript. All authors contributed to the manuscript revision.

Funding: This research received no external funding.

Acknowledgments: K.B. is the recipient of a Clinical Doctoral Scholarship of the academic fund of UZ Leuven. B.V.D.S. and R.D. are holder of a Fundamental Clinical Investigatorship of FWO Flanders.

Conflicts of Interest: The authors declare no conflict of interest.

\section{References}

1. Devlieger, R.; Benhalima, K.; Damm, P.; Van Assche, A.; Mathieu, C.; Mahmood, T.; Dunne, F.; Bogaerts, A. Maternal obesity in europe: Where do we stand and how to move forward?: A scientific paper commissioned by the european board and college of obstetrics and gynaecology (ebcog). Eur. J. Obstet. Gynecol. Reprod. Biol. 2016, 201, 203-208. [CrossRef] [PubMed]

2. Torloni, M.R.; Betran, A.P.; Horta, B.L.; Nakamura, M.U.; Atallah, A.N.; Moron, A.F.; Valente, O. Prepregnancy bmi and the risk of gestational diabetes: A systematic review of the literature with meta-analysis. Obes. Rev. 2009, 10, 194-203. [CrossRef] [PubMed]

3. Heslehurst, N.; Simpson, H.; Ells, L.J.; Rankin, J.; Wilkinson, J.; Lang, R.; Brown, T.J.; Summerbell, C.D. The impact of maternal bmi status on pregnancy outcomes with immediate short-term obstetric resource implications: A meta-analysis. Obes. Rev. 2008, 9, 635-683. [CrossRef] [PubMed]

4. Willis, K.; Lieberman, N.; Sheiner, E. Pregnancy and neonatal outcome after bariatric surgery. Best Pract. Res. Clin. Obstet. Gynaecol. 2015, 29, 133-144. [CrossRef] [PubMed]

5. American Diabetes, A. Diagnosis and classification of diabetes mellitus. Diabetes Care 2009, 32 (Suppl. 1), S62-S67. [CrossRef]

6. International Association of Diabetes; Pregnancy Study Groups Consensus, Panel; Metzger, B.E.; Gabbe, S.G.; Persson, B.; Buchanan, T.A.; Catalano, P.A.; Damm, P.; Dyer, A.R.; Leiva, A.; et al. International association of diabetes and pregnancy study groups recommendations on the diagnosis and classification of hyperglycemia in pregnancy. Diabetes Care 2010, 33, 676-682. [CrossRef] [PubMed]

7. American Diabetes Association. Standards of medical care in diabetes-2013. Diabetes Care 2013, 36 (Suppl. 1), S11-S66. [CrossRef] [PubMed]

8. Hod, M.; Kapur, A.; Sacks, D.A.; Hadar, E.; Agarwal, M.; Di Renzo, G.C.; Cabero Roura, L.; McIntyre, H.D.; Morris, J.L.; Divakar, H. The international federation of gynecology and obstetrics (figo) initiative on gestational diabetes mellitus: A pragmatic guide for diagnosis, management and care. Int. J. Gynaecol. Obstet. 2015, 131 (Suppl. 3), S173-S211. [CrossRef]

9. Blumer, I.; Hadar, E.; Hadden, D.R.; Jovanovic, L.; Mestman, J.H.; Murad, M.H.; Yogev, Y. Diabetes and pregnancy: An endocrine society clinical practice guideline. J. Clin. Endocrinol. Metab. 2013, 98, 4227-4249. [CrossRef] [PubMed] 
10. Catalano, P.M. Trying to understand gestational diabetes. Diabet. Med. 2014, 31, 273-281. [CrossRef] [PubMed]

11. Baz, B.; Riveline, J.P.; Gautier, J.F. Endocrinology of pregnancy: Gestational diabetes mellitus: Definition, aetiological and clinical aspects. Eur. J. Endocrinol. 2016, 174, 43-51. [CrossRef] [PubMed]

12. Crowther, C.A.; Hiller, J.E.; Moss, J.R.; McPhee, A.J.; Jeffries, W.S.; Robinson, J.S.; Australian Carbohydrate Intolerance Study in Pregnant Women Trial Group. Effect of treatment of gestational diabetes mellitus on pregnancy outcomes. N. Engl. J. Med. 2005, 352, 2477-2486. [CrossRef] [PubMed]

13. Landon, M.B.; Spong, C.Y.; Thom, E.; Carpenter, M.W.; Ramin, S.M.; Casey, B.; Wapner, R.J.; Varner, M.W.; Rouse, D.J.; Thorp, J.M., Jr.; et al. A multicenter, randomized trial of treatment for mild gestational diabetes. N. Engl. J. Med. 2009, 361, 1339-1348. [CrossRef] [PubMed]

14. Bellamy, L.; Casas, J.P.; Hingorani, A.D.; Williams, D. Type 2 diabetes mellitus after gestational diabetes: A systematic review and meta-analysis. Lancet 2009, 373, 1773-1779. [CrossRef]

15. Philipps, L.H.; Santhakumaran, S.; Gale, C.; Prior, E.; Logan, K.M.; Hyde, M.J.; Modi, N. The diabetic pregnancy and offspring bmi in childhood: A systematic review and meta-analysis. Diabetologia 2011, 54, 1957-1966. [CrossRef] [PubMed]

16. Landon, M.B.; Rice, M.M.; Varner, M.W.; Casey, B.M.; Reddy, U.M.; Wapner, R.J.; Rouse, D.J.; Biggio, J.R., Jr.; Thorp, J.M.; Chien, E.K.; et al. Mild gestational diabetes mellitus and long-term child health. Diabetes Care 2015, 38, 445-452. [CrossRef] [PubMed]

17. HAPO Study Cooperative Research Group; Metzger, B.E.; Lowe, L.P.; Dyer, A.R.; Trimble, E.R.; Chaovarindr, U.; Coustan, D.R.; Hadden, D.R.; McCance, D.R.; Hod, M.; et al. Hyperglycemia and adverse pregnancy outcomes. N. Engl. J. Med. 2008, 358, 1991-2002. [CrossRef] [PubMed]

18. Diagnostic criteria and classification of hyperglycaemia first detected in pregnancy: A world health organization guideline. Diabetes Res. Clin. Pract. 2014, 103, 341-363. [CrossRef]

19. Poston, L.; Bell, R.; Croker, H.; Flynn, A.C.; Godfrey, K.M.; Goff, L.; Hayes, L.; Khazaezadeh, N.; Nelson, S.M.; Oteng-Ntim, E.; et al. Effect of a behavioural intervention in obese pregnant women (the upbeat study): A multicentre, randomised controlled trial. Lancet Diabetes Endocrinol. 2015, 3, 767-777. [CrossRef]

20. Simmons, D.; Devlieger, R.; van Assche, A.; Jans, G.; Galjaard, S.; Corcoy, R.; Adelantado, J.M.; Dunne, F.; Desoye, G.; Harreiter, J.; et al. Effect of physical activity and/or healthy eating on gdm risk: The dali lifestyle study. J. Clin. Endocrinol. Metab. 2017, 102, 903-913. [CrossRef] [PubMed]

21. Gilmartin, A.B.; Ural, S.H.; Repke, J.T. Gestational diabetes mellitus. Rev. Obstet. Gynecol. 2008, 1, $129-134$. [PubMed]

22. Catalano, P.M.; McIntyre, H.D.; Cruickshank, J.K.; McCance, D.R.; Dyer, A.R.; Metzger, B.E.; Lowe, L.P.; Trimble, E.R.; Coustan, D.R.; Hadden, D.R.; et al. The hyperglycemia and adverse pregnancy outcome study: Associations of gdm and obesity with pregnancy outcomes. Diabetes Care 2012, 35, 780-786. [CrossRef] [PubMed]

23. Black, M.H.; Sacks, D.A.; Xiang, A.H.; Lawrence, J.M. The relative contribution of prepregnancy overweight and obesity, gestational weight gain and iadpsg-defined gestational diabetes mellitus to fetal overgrowth. Diabetes Care 2013, 36, 56-62. [CrossRef] [PubMed]

24. Koivusalo, S.B.; Rono, K.; Klemetti, M.M.; Roine, R.P.; Lindstrom, J.; Erkkola, M.; Kaaja, R.J.; Poyhonen-Alho, M.; Tiitinen, A.; Huvinen, E.; et al. Gestational diabetes mellitus can be prevented by lifestyle intervention: The finnish gestational diabetes prevention study (radiel): A randomized controlled trial. Diabetes Care 2016, 39, 24-30. [CrossRef] [PubMed]

25. Dodd, J.M.; Turnbull, D.; McPhee, A.J.; Deussen, A.R.; Grivell, R.M.; Yelland, L.N.; Crowther, C.A.; Wittert, G.; Owens, J.A.; Robinson, J.S.; et al. Antenatal lifestyle advice for women who are overweight or obese: Limit randomised trial. BMJ 2014, 348, g1285. [CrossRef] [PubMed]

26. Hng, K.N.; Ang, Y.S. Overview of bariatric surgery for the physician. Clin. Med. 2012, 12, 435-440. [CrossRef]

27. Sjostrom, L.; Narbro, K.; Sjostrom, C.D.; Karason, K.; Larsson, B.; Wedel, H.; Lystig, T.; Sullivan, M.; Bouchard, C.; Carlsson, B.; et al. Effects of bariatric surgery on mortality in Sedish obese subjects. N. Engl. J. Med. 2007, 357, 741-752. [CrossRef] [PubMed]

28. Santulli, P.; Mandelbrot, L.; Facchiano, E.; Dussaux, C.; Ceccaldi, P.F.; Ledoux, S.; Msika, S. Obstetrical and neonatal outcomes of pregnancies following gastric bypass surgery: A retrospective cohort study in a Fench referral centre. Obes. Surg. 2010, 20, 1501-1508. [CrossRef] [PubMed] 
29. Devlieger, R.; Jans, G.; Matthys, C. Outcomes of pregnancy after bariatric surgery. N. Engl. J. Med. 2015, 372, 2266. [PubMed]

30. Johansson, K.; Cnattingius, S.; Naslund, I.; Roos, N.; Trolle Lagerros, Y.; Granath, F.; Stephansson, O.; Neovius, M. Outcomes of pregnancy after bariatric surgery. N. Engl. J. Med. 2015, 372, 814-824. [CrossRef] [PubMed]

31. Roos, N.; Neovius, M.; Cnattingius, S.; Trolle Lagerros, Y.; Saaf, M.; Granath, F.; Stephansson, O. Perinatal outcomes after bariatric surgery: Nationwide population based matched cohort study. BMJ 2013, 347, f6460. [CrossRef] [PubMed]

32. Kjaer, M.M.; Lauenborg, J.; Breum, B.M.; Nilas, L. The risk of adverse pregnancy outcome after bariatric surgery: A nationwide register-based matched cohort study. Am. J. Obstet. Gynecol. 2013, 208, 464.e1-464.e5. [CrossRef] [PubMed]

33. Kwong, W.; Tomlinson, G.; Feig, D.S. Maternal and neonatal outcomes after bariatric surgery; a systematic review and meta-analysis: Do the benefits outweigh the risks? Am. J. Obstet. Gynecol. 2018, 218, 573-580. [CrossRef] [PubMed]

34. Facchiano, E.; Iannelli, A.; Santulli, P.; Mandelbrot, L.; Msika, S. Pregnancy after laparoscopic bariatric surgery: Comparative study of adjustable gastric banding and roux-en-y gastric bypass. Surg. Obes. Relat. Dis. 2012, 8, 429-433. [CrossRef] [PubMed]

35. Sheiner, E.; Balaban, E.; Dreiher, J.; Levi, I.; Levy, A. Pregnancy outcome in patients following different types of bariatric surgeries. Obes. Surg. 2009, 19, 1286-1292. [CrossRef] [PubMed]

36. Ducarme, G.; Parisio, L.; Santulli, P.; Carbillon, L.; Mandelbrot, L.; Luton, D. Neonatal outcomes in pregnancies after bariatric surgery: A retrospective multi-centric cohort study in three French referral centers. J. Matern. Fetal Neonatal Med. 2013, 26, 275-278. [CrossRef] [PubMed]

37. Jans, G.; Matthys, C.; Bogaerts, A.; Lannoo, M.; Verhaeghe, J.; Van der Schueren, B.; Devlieger, R. Maternal micronutrient deficiencies and related adverse neonatal outcomes after bariatric surgery: A systematic review. Adv. Nutr. 2015, 6, 420-429. [CrossRef] [PubMed]

38. Burke, A.E.; Bennett, W.L.; Jamshidi, R.M.; Gilson, M.M.; Clark, J.M.; Segal, J.B.; Shore, A.D.; Magnuson, T.H.; Dominici, F.; Wu, A.W.; et al. Reduced incidence of gestational diabetes with bariatric surgery. J. Am. Coll. Surg. 2010, 211, 169-175. [CrossRef] [PubMed]

39. Sheiner, E.; Edri, A.; Balaban, E.; Levi, I.; Aricha-Tamir, B. Pregnancy outcome of patients who conceive during or after the first year following bariatric surgery. Am. J. Obstet. Gynecol. 2011, 204, 50.e1-50.e6. [CrossRef] [PubMed]

40. Aricha-Tamir, B.; Weintraub, A.Y.; Levi, I.; Sheiner, E. Downsizing pregnancy complications: A study of paired pregnancy outcomes before and after bariatric surgery. Surg. Obes. Relat. Dis. 2012, 8, 434-439. [CrossRef] [PubMed]

41. Amsalem, D.; Aricha-Tamir, B.; Levi, I.; Shai, D.; Sheiner, E. Obstetric outcomes after restrictive bariatric surgery: What happens after 2 consecutive pregnancies? Surg. Obes. Relat. Dis. 2014, 10, 445-449. [CrossRef] [PubMed]

42. Josefsson, A.; Bladh, M.; Wirehn, A.B.; Sydsjo, G. Risk for congenital malformations in offspring of women who have undergone bariatric surgery. A national cohort. BJOG 2013, 120, 1477-1482. [CrossRef] [PubMed]

43. Berlac, J.F.; Skovlund, C.W.; Lidegaard, O. Obstetrical and neonatal outcomes in women following gastric bypass: A danish national cohort study. Acta. Obstet. Gynecol. Scand. 2014, 93, 447-453. [CrossRef] [PubMed]

44. Adams, T.D.; Hammoud, A.O.; Davidson, L.E.; Laferrere, B.; Fraser, A.; Stanford, J.B.; Hashibe, M.; Greenwood, J.L.; Kim, J.; Taylor, D.; et al. Maternal and neonatal outcomes for pregnancies before and after gastric bypass surgery. Int. J. Obes. 2015, 39, 686-694. [CrossRef] [PubMed]

45. Abenhaim, H.A.; Alrowaily, N.; Czuzoj-Shulman, N.; Spence, A.R.; Klam, S.L. Pregnancy outcomes in women with bariatric surgery as compared with morbidly obese women. J. Matern. Fetal Neonatal Med. 2016, 29, 3596-3601. [CrossRef] [PubMed]

46. Shai, D.; Shoham-Vardi, I.; Amsalem, D.; Silverberg, D.; Levi, I.; Sheiner, E. Pregnancy outcome of patients following bariatric surgery as compared with obese women: A population-based study. J. Matern. Fetal Neonatal Med. 2014, 27, 275-278. [CrossRef] [PubMed]

47. Parker, M.H.; Berghella, V.; Nijjar, J.B. Bariatric surgery and associated adverse pregnancy outcomes among obese women. J. Matern. Fetal Neonatal Med. 2016, 29, 1747-1750. [CrossRef] [PubMed] 
48. Chevrot, A.; Kayem, G.; Coupaye, M.; Lesage, N.; Msika, S.; Mandelbrot, L. Impact of bariatric surgery on fetal growth restriction: Experience of a perinatal and bariatric surgery center. Am. J. Obstet. Gynecol. 2016, 214, 655.e1-655.e7. [CrossRef] [PubMed]

49. Lapolla, A.; Marangon, M.; Dalfra, M.G.; Segato, G.; De Luca, M.; Fedele, D.; Favretti, F.; Enzi, G.; Busetto, L. Pregnancy outcome in morbidly obese women before and after laparoscopic gastric banding. Obes. Surg. 2010, 20, 1251-1257. [CrossRef] [PubMed]

50. Yi, X.Y.; Li, Q.F.; Zhang, J.; Wang, Z.H. A meta-analysis of maternal and fetal outcomes of pregnancy after bariatric surgery. Int. J. Gynaecol. Obstet. 2015, 130, 3-9. [CrossRef] [PubMed]

51. Adam, S.; Ammori, B.; Soran, H.; Syed, A.A. Pregnancy after bariatric surgery: Screening for gestational diabetes. BMJ 2017, 356, j533. [CrossRef] [PubMed]

52. Andrade, H.F.; Pedrosa, W.; Diniz Mde, F.; Passos, V.M. Adverse effects during the oral glucose tolerance test in post-bariatric surgery patients. Arch. Endocrinol. Metab. 2016, 60, 307-313. [CrossRef] [PubMed]

53. Feichtinger, M.; Stopp, T.; Hofmann, S.; Springer, S.; Pils, S.; Kautzky-Willer, A.; Kiss, H.; Eppel, W.; Tura, A.; Bozkurt, L.; et al. Altered glucose profiles and risk for hypoglycaemia during oral glucose tolerance testing in pregnancies after gastric bypass surgery. Diabetologia 2017, 60, 153-157. [CrossRef] [PubMed]

54. Freitas, C.; Araujo, C.; Caldas, R.; Lopes, D.S.; Nora, M.; Monteiro, M.P. Effect of new criteria on the diagnosis of gestational diabetes in women submitted to gastric bypass. Surg. Obes. Relat. Dis. 2014, 10, 1041-1046. [CrossRef] [PubMed]

55. Rottenstreich, A.; Elazary, R.; Ezra, Y.; Kleinstern, G.; Beglaibter, N.; Elchalal, U. Hypoglycemia during oral glucose tolerance test among post-bariatric surgery pregnant patients: Incidence and perinatal significance. Surg. Obes. Relat. Dis. 2018, 14, 347-353. [CrossRef] [PubMed]

56. Benhalima, K.; Mathieu, C.; Damm, P.; Van Assche, A.; Devlieger, R.; Desoye, G.; Corcoy, R.; Mahmood, T.; Nizard, J.; Savona-Ventura, C.; et al. A proposal for the use of uniform diagnostic criteria for gestational diabetes in europe: An opinion paper by the european board \& college of obstetrics and gynaecology (ebcog). Diabetologia 2015, 58, 1422-1429. [PubMed]

57. Agarwal, M.M.; Punnose, J.; Dhatt, G.S. Gestational diabetes: Problems associated with the oral glucose tolerance test. Diabetes Res. Clin. Pract. 2004, 63, 73-74. [CrossRef] [PubMed]

58. Bonis, C.; Lorenzini, F.; Bertrand, M.; Parant, O.; Gourdy, P.; Vaurs, C.; Cazals, L.; Ritz, P.; Hanaire, H. Glucose profiles in pregnant women after a gastric bypass: Findings from continuous glucose monitoring. Obes. Surg. 2016, 26, 2150-2155. [CrossRef] [PubMed]

59. Novodvorsky, P.; Walkinshaw, E.; Rahman, W.; Gordon, V.; Towse, K.; Mitchell, S.; Selvarajah, D.; Madhuvrata, P.; Munir, A. Experience with freestyle libre flash glucose monitoring system in management of refractory dumping syndrome in pregnancy shortly after bariatric surgery. Endocrinol. Diabetes Metab. Case Rep. 2017, 2017. [CrossRef] [PubMed]

60. Association, A.D. Standards of medical care in diabetes. Diabetes Care 2017, 40, 120-127.

61. Benhalima, K.; Devlieger, R.; Van Assche, A. Screening and management of gestational diabetes. Best Pract. Res. Clin. Obstet. Gynaecol. 2015, 29, 339-349. [CrossRef] [PubMed]

62. Rowan, J.A.; Hague, W.M.; Gao, W.; Battin, M.R.; Moore, M.P.; Mi, G.T.I. Metformin versus insulin for the treatment of gestational diabetes. N. Engl. J. Med. 2008, 358, 2003-2015. [CrossRef] [PubMed]

63. Balsells, M.; Garcia-Patterson, A.; Sola, I.; Roque, M.; Gich, I.; Corcoy, R. Glibenclamide, metformin and insulin for the treatment of gestational diabetes: A systematic review and meta-analysis. BMJ 2015, 350, h102. [CrossRef] [PubMed]

64. Hanem, L.G.E.; Stridsklev, S.; Júlíusson, P.B.; Salvesen, Ø.; Roelants, M.; Carlsen, S.M.; Ødegård, R.; Vanky, E. Metformin use in pcos pregnancies increases the risk of offspring overweight at 4 years of age; follow-up of two rcts. J. Clinl. Endocrino. Meta. 2018, 103, 1612-1621. [CrossRef] [PubMed]

65. Mechanick, J.I.; Youdim, A.; Jones, D.B.; Garvey, W.T.; Hurley, D.L.; McMahon, M.M.; Heinberg, L.J.; Kushner, R.; Adams, T.D.; Shikora, S.; et al. Clinical practice guidelines for the perioperative nutritional, metabolic and nonsurgical support of the bariatric surgery patient-2013 update: Cosponsored by american association of clinical endocrinologists, the obesity society and american society for metabolic \& bariatric surgery. Endocr. Pract. 2013, 19, 337-372. [PubMed]

66. Heber, D.; Greenway, F.L.; Kaplan, L.M.; Livingston, E.; Salvador, J.; Still, C.; Endocrine, S. Endocrine and nutritional management of the post-bariatric surgery patient: An endocrine society clinical practice guideline. J. Clin. Endocrinol. Metab. 2010, 95, 4823-4843. [CrossRef] [PubMed] 
67. Parent, B.; Martopullo, I.; Weiss, N.S.; Khandelwal, S.; Fay, E.E.; Rowhani-Rahbar, A. Bariatric surgery in women of childbearing age, timing between an operation and birth and associated perinatal complications. JAMA Surg. 2017, 152, 1-8. [CrossRef] [PubMed]

68. Yau, P.O.; Parikh, M.; Saunders, J.K.; Chui, P.; Zablocki, T.; Welcome, A.U. Pregnancy after bariatric surgery: The effect of time-to-conception on pregnancy outcomes. Surg. Obes. Relat. Dis. 2017, 13, 1899-1905. [CrossRef] [PubMed]

69. Rasteiro, C.; Araujo, C.; Cunha, S.; Caldas, R.; Mesquita, J.; Seixas, A.; Augusto, N.; Ramalho, C. Influence of time interval from bariatric surgery to conception on pregnancy and perinatal outcomes. Obes. Surg. 2018. Available online: https:/ /link.springer.com/article/10.1007/s11695-018-3395-5 (accessed on 20 June 2018). [CrossRef] [PubMed]

70. Galazis, N.; Docheva, N.; Simillis, C.; Nicolaides, K.H. Maternal and neonatal outcomes in women undergoing bariatric surgery: A systematic review and meta-analysis. Eur. J. Obstet. Gynecol. Reprod. Biol. 2014, 181, 45-53. [CrossRef] [PubMed]

71. Mead, N.C.; Sakkatos, P.; Sakellaropoulos, G.C.; Adonakis, G.L.; Alexandrides, T.K.; Kalfarentzos, F. Pregnancy outcomes and nutritional indices after 3 types of bariatric surgery performed at a single institution. Surg. Obes. Relat. Dis. 2014, 10, 1166-1173. [CrossRef] [PubMed]

72. Faintuch, J.; Dias, M.C.; de Souza Fazio, E.; de Oliveira, F.C.; Nomura, R.M.; Zugaib, M.; Cecconello, I. Pregnancy nutritional indices and birth weight after roux-en-y gastric bypass. Obes. Surg. 2009, 19, 583-589. [CrossRef] [PubMed]

73. Jans, G.; Guelinckx, I.; Voets, W.; Galjaard, S.; Van Haard, P.M.; Vansant, G.M.; Devlieger, R. Vitamin k1 monitoring in pregnancies after bariatric surgery: A prospective cohort study. Surg. Obes. Relat. Dis. 2014, 10, 885-890. [CrossRef] [PubMed]

74. Haider, B.A.; Bhutta, Z.A. Multiple-micronutrient supplementation for women during pregnancy. Cochrane Database Syst. Rev. 2017, 4, CD004905. [CrossRef] [PubMed]

(C) 2018 by the authors. Licensee MDPI, Basel, Switzerland. This article is an open access article distributed under the terms and conditions of the Creative Commons Attribution (CC BY) license (http:// creativecommons.org/licenses/by/4.0/). 